\title{
Ultrasonic tomography of SiC-based materials synthesized by spark plasma sintering of preceramic paper
}

\author{
E P Sedanova ${ }^{1}$, M S Syrtanov ${ }^{1}$, E B Kashkarov ${ }^{1}$, A S Yurovskikh ${ }^{2}$ \\ and $\mathbf{N}$ Travitzky ${ }^{1,3}$ \\ ${ }^{1}$ National Research Tomsk Polytechnic University, Tomsk, Russia \\ ${ }^{2}$ Ural Federal University named after the first President of Russia B.N. Yeltsin, \\ Yekaterinburg, Russia \\ ${ }^{3}$ Friedrich-Alexander-Universität Erlangen-Nürnberg, Erlangen, Germany
}

eps4@tpu.ru

\begin{abstract}
This paper is devoted to study a structure of SiC-based materials using ultrasonic tomography method. The SiC-based materials were fabricated from preceramic paper using spark plasma sintering (SPS) method. Also as part of the study the Young`s modulus and density of sintered materials were determined and the effect of sintering pressure changing to this parameters value was investigated. The preceramic paper is a composite material including a matrix of organic cellulose fibers and inorganic powder filler ( $\mathrm{SiC}$ ). The sintering temperature and pressure were $2373 \mathrm{~K}$ and $20-40 \mathrm{MPa}$, respectively. The holding time for the sintering process was $10 \mathrm{~min}$. The density of sintered materials was investigated by the hydrostatic weighing method. Ultrasonic tomography was implemented using of singlechannel sensor at $10 \mathrm{MHz}$ frequency.
\end{abstract}

\section{Introduction}

One of the key development factors for industry is an ensuring the safe operation of installations and constructions in facilities. Accordingly, much attention is paid to the design of new materials, which properties meet the requirements for finished products and are preserved during the operation of products. The potential to use $\mathrm{SiC}$-based materials in industry is due to the physicochemical properties of this compound: heat resistance, mechanical strength at a relatively low material density, high corrosion resistance etc. [1]. These characteristics cause the widespread application of SiC-based compounds as materials for gas turbines, elements of combustion engines, machining tools as well as constructional materials of the nuclear industry, aircraft and shipbuilding.

The development of new materials for the industry involves the creation of a measures system to monitor the quality of products made. The defect arising in the material structure can significantly affect the mechanical characteristics of the products. It can lead to further incidents on facility with a defective product [2]. Timely non-destructive testing of products allows to detect internal defects and to prevent the further increasing of their size. Ultrasonic tomography is one of the commonly used method for non-destructive testing in industry. The advantages of ultrasonic tomography are effectiveness, accuracy and safety of personnel during tomography procedure [3]. In addition, the ultrasonic effect to material is used for determining the elastic properties of the material (Young's modulus) without destroying the experimental sample [4]. 
This paper describes the opportunity to conduct ultrasonic tomography of SiC-based materials synthesized by SPS of preceramic papers. Moreover, the ultrasonic tomography database can be used to determine the Young's modulus of the materials for further study the sintering regime influence to its value.

\section{Materials and methods}

\subsection{Sample preparation and sintering procedure}

The preceramic paper sheets with inorganic filler ( $\mathrm{SiC}$ powder) were fabricated by a laboratory dynamic hand-sheet former (Dynamic hand-sheet former D7, Sumet Systems GmbH, Germany). The technology of preceramic paper fabrication and study of its mechanical properties have been described in ref. $[5,6]$. For sintering procedure, the preceramic paper was cut into the round sheets of $20 \mathrm{~mm}$ in diameter. The samples for sintering were made in a form of stacks of 12 preceramic round layers.

The sintering procedure was conducted by using HPD25 SPS-equipment (FCT Systeme GmbH, Germany). The scheme of sintering equipment is shown in Figure 1 [7].

The feature of this method is the passing of powerful pulse direct current through the material. That creates a spark plasma discharge in the gaps between the material particles promoting the formation of interparticle contacts, which stimulates the diffusion process during sintering. In addition, the sintering of materials is conducted without using of additional binders due to the samples are pressured before sintering [8]. The stack of 12 layers of preceramic paper is placed between two graphite punches in a graphite die. A graphite foil is introduced at the punch/sample interface to ensure good electrical contacts. The sintering of materials was conducted in a vacuum, SPS parameters are shown in Table 1.

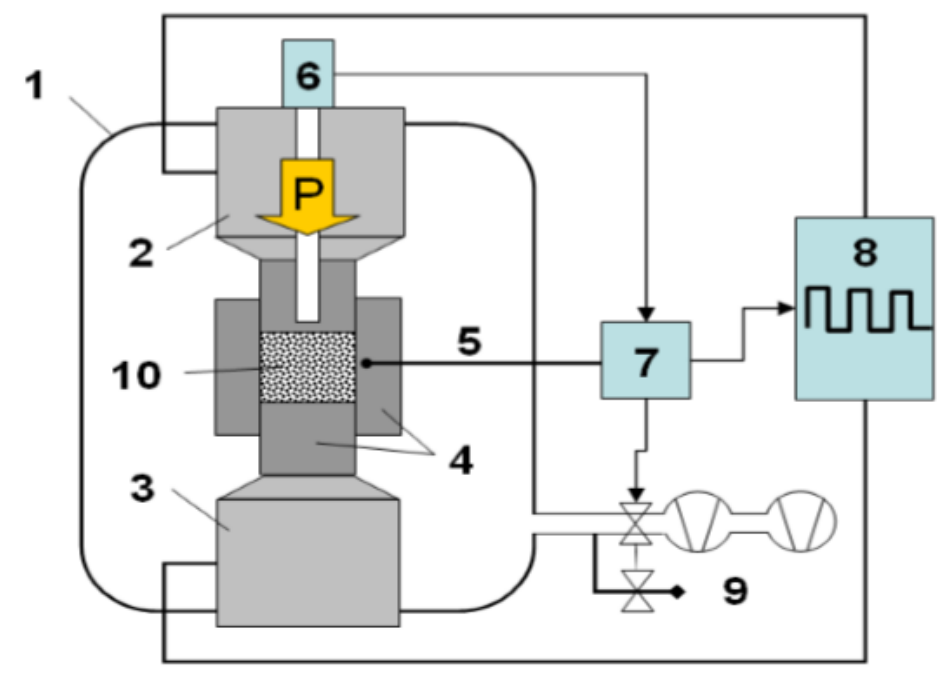

Figure 1. Scheme of SPS-equipment: 1 - chamber, 2 - movable punch, 3 - lower punch, 4 - graphite die, 5 - thermal couple, 6 pyrometer, 7 - system controller, 8 - direct-current pulse generator, 9 - furnace atmosphere systems, 10 - sintered material.

Table 1. SPS-sintering regimes for samples of preceramic paper with SiC-filler.

\begin{tabular}{ccc}
\hline Pressure $(\mathrm{MPa})$ & Sintering temperature $(\mathrm{K})$ & Holding time $(\mathrm{min})$ \\
\hline 20,40 & 2373 & 10 \\
\hline
\end{tabular}


The sintered samples are dense monolithic disks with the diameter of $20 \mathrm{~mm}$. Their surfaces were machined to remove a graphite foil for further study. The surface machining included procedures of grinding and polishing by using silicon-carbide papers marked by ISO from 1500 to 4000 on both sides of the samples. After polishing, the samples were ultrasonically cleaned with acetone for $15 \mathrm{~min}$.

\subsection{Hydrostatic weighing}

The density of sintered materials was determined by hydrostatic weighting directly after machining of the surfaces. During the hydrostatic weighting procedure the kerosene with density $0.784 \mathrm{~g} / \mathrm{cm}^{3}\left(20^{\circ} \mathrm{C}\right)$ was used as a liquid. The density of samples was calculated by the following formula:

$$
\rho=\frac{m \cdot 0.784 \mathrm{~g} / \mathrm{sm}^{3}}{\left(m_{a}-m_{k}\right)}
$$

where $m$ - mass of sample; $m_{k}$ - mass of sample in kerosene; $m_{a}$ - mass of kerosened sample in air.

\subsection{Ultrasonic testing}

The ultrasonic testing procedure was implemented using an ultrasonic tomography system shown in Figure 2. The installation consists of ultrasonic electronic unit, scanner and immersion tank. Ultrasonic unit includes the unit of path control of scanner and PC for displaying the tomography results in realtime.

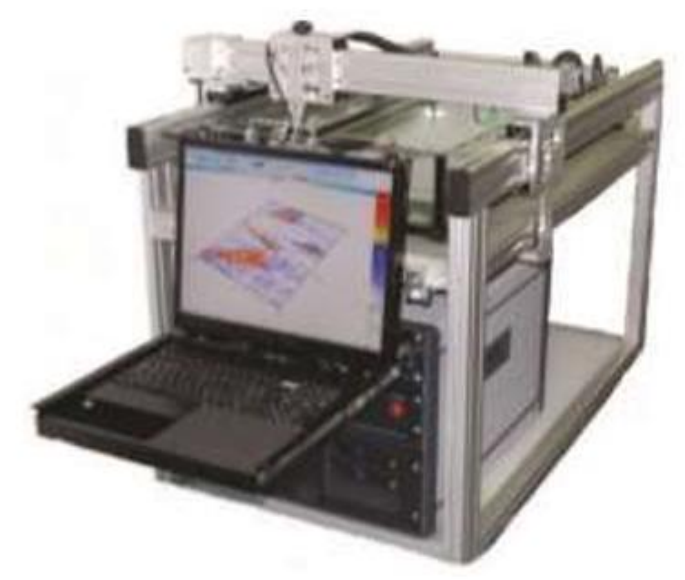

Figure 2. Ultrasonic tomography system IDealSystem3D.

For tomography of the sintered materials, the ultrasound single-channel $10 \mathrm{MHz}$ sensor was used. To start the tomography procedure in automatic mode it is necessary to arrange the sensor to starting point (0-point) above the surface of tomography object in manual mode. After setting the scanning modes, ultrasonic tomography system starts the procedure by moving scanner above the sample in immersion liquid (water) as it is shown in Figure 3. 


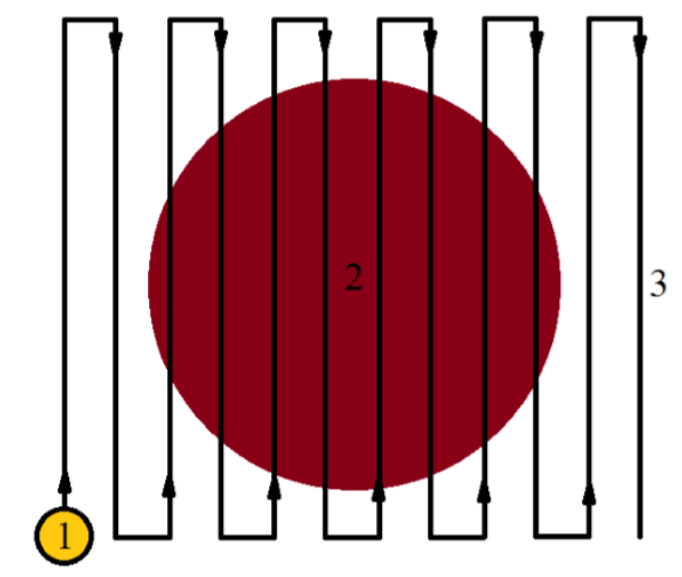

Figure 3. Ultrasonic tomography process: 1 - scanner; 2 - object of tomography; 3 - motion path of sensor.

The ultrasonic tomography results were processed by the Time of Flight (TOF) method. The main characteristic of this method is trip-time of the ultrasonic signal in the material from the surface of sample to the back surface reflection or the internal defect edge. The obtained signal trip-time values were processed by the I-Deal Studio software for visualization the sample B-scans. Also, the data of ultrasonic tomography results were processed in the MATLAB package to determine the acoustic velocity of signal in material and to calculate the Young`s modulus of sintered materials by the acoustic resonance method [4]. According to this method, the Young`s modulus is determined by the formula:

$$
E=v^{2} \cdot \rho,
$$

where $v$-acoustic velocity of material; $\rho$ - density of material.

\section{Results and discussion}

\subsection{Hydrostatic weighing results}

The results of density measurements for the sintered materials are shown in Table 2. Based on the obtained values, it can be seen that the density of the SiC-based materials increases with pressure applied to the preceramic paper during sintering.

Table 2. Hydrostatic weighting results for the sintered samples.

\begin{tabular}{ccccc}
\hline $\begin{array}{c}\text { Pressure } \\
(\mathrm{MPa})\end{array}$ & $\begin{array}{c}\text { Mass of } \\
\text { sample }(\mathrm{g})\end{array}$ & $\begin{array}{c}\text { Mass of sample in } \\
\text { kerosene }(\mathrm{g})\end{array}$ & $\begin{array}{c}\text { Mass of wetted sample } \\
\text { in air }(\mathrm{g})\end{array}$ & $\begin{array}{c}\text { Density of sample } \\
\left(\mathrm{g} / \mathrm{sm}^{3}\right)\end{array}$ \\
\hline 20 & 1.963 & 1.478 & 2.241 & 2.087 \\
40 & 1.748 & 1.330 & 1.915 & 2.331 \\
\hline
\end{tabular}

\subsection{Ultrasonic testing results}

The results of ultrasonic tomography of the samples sintered under $20 \mathrm{MPa}$ and $40 \mathrm{MPa}$ are shown in Figures 4 and 5, respectively. As can be seen from the B-scan images (cross section), the samples are a monoliths and do not contain in structure large defects such as delamination and cracks. However, one should not exclude the presence of defects such as pores of small diameters. Due to the lack of a preliminary calibration procedure for the sensor, the ultrasonic tomography equipment may be insensitive to this type of defects. Pores influence to SiC-based materials will be considered in further study. 


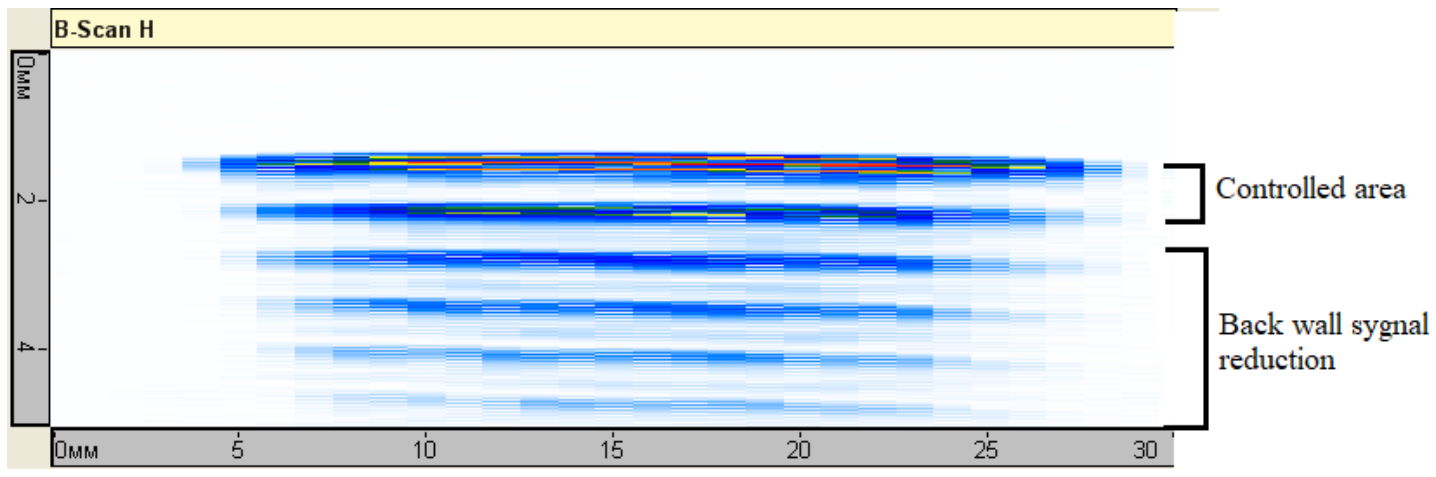

Figure 4. B-scan of SiC-based material sintered at $2372 \mathrm{~K}$ under $20 \mathrm{MPa}$ for $10 \mathrm{~min}$.

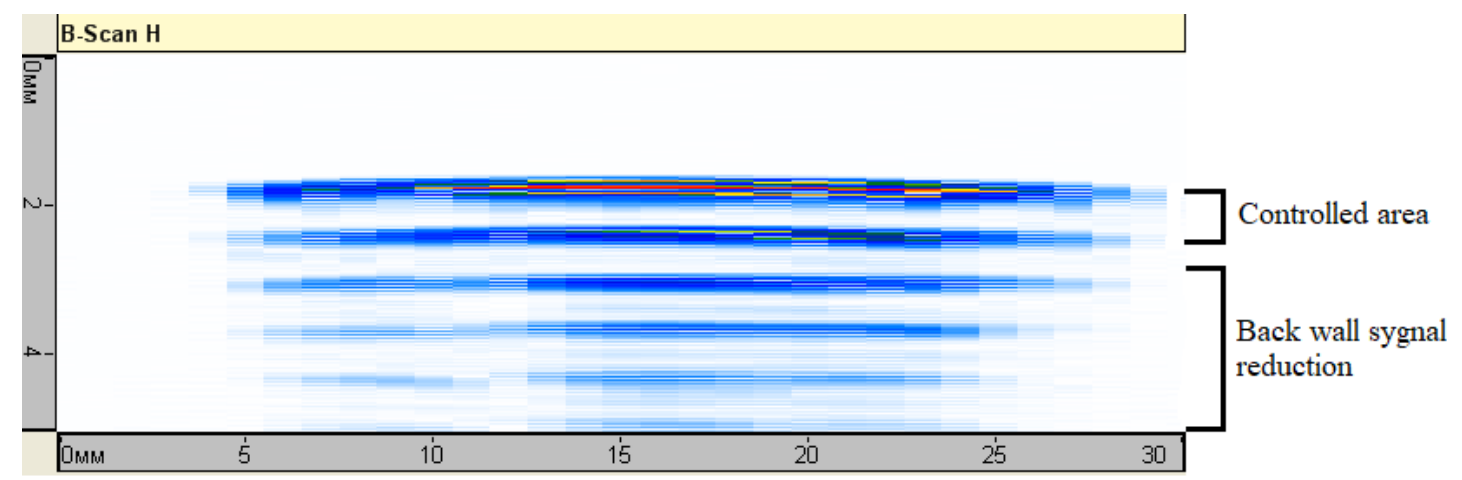

Figure 5. B-scan of SiC-based material sintered at $2372 \mathrm{~K}$ under $40 \mathrm{MPa}$ for $10 \mathrm{~min}$.

\subsection{Young `s modulus}

After completion of the ultrasonic tomography, the data of signal trip-time of the samples obtained from the ultrasonic sensor was analyzed using MATLAB software. The trip-time of the ultrasonic wave in the sintered materials were determined by the TOF method. The acoustic velocities of samples were determined from the ratio of the sample thickness to the trip-time. Then the value of Young's modulus for each sample was calculated using Formula (1). The calculated values are presented in Table 3 .

Table 3. Results of TOF and determination of acoustic signal trip-time and Young`s modulus of the samples.

\begin{tabular}{ccccc}
\hline $\begin{array}{c}\text { Pressure } \\
(\mathrm{MPa})\end{array}$ & $\begin{array}{c}\text { Thickness of sample after } \\
\text { machining }(\mathrm{mm})\end{array}$ & $\begin{array}{c}\text { Acoustic signal } \\
\text { trip-time }(\mu \mathrm{s})\end{array}$ & $\begin{array}{c}\text { Acoustic velocity } \\
(\mathrm{m} / \mathrm{s})\end{array}$ & $\begin{array}{c}\text { Young`s } \\
\text { modulus } \\
(\mathrm{GPa})\end{array}$ \\
\hline 20 & 2.81 & 0.86 & 3267.44 & 223 \\
40 & 2.85 & 0.84 & 3392.86 & 268 \\
\hline
\end{tabular}

From the analysis of the obtained results, it follows that the increase in sintering pressure leads to increase in the acoustic velocity and correspondingly the Young's modulus of the synthesized material. The latter contributes to the higher density of the SiC sintered at $40 \mathrm{MPa}$. The obtained values of the acoustic velocity in the synthesized materials is lower than for monolithic SiC-ceramics [9], which is attributed to the lower density of the sintered materials. 


\section{Conclusion}

The SiC-based ceramic material was successfully synthesized by SPS of preceramic papers with SiCpowder filler at $2373 \mathrm{~K}$ and $20-40 \mathrm{MPa}$ pressure for 10 minutes. Ultrasonic tomography of the SiCbased materials was conducted using the TOF method. The Young's modulus of the synthesized materials was determined for each sample based on the acoustic velocity measurements. It was found that the Young's modulus increases from $223 \mathrm{MPa}$ to $268 \mathrm{MPa}$ with increasing sintering pressure, which is caused by an increase in the density of the material from $2.09 \mathrm{~g} / \mathrm{cm}^{3}$ to $2.33 \mathrm{~g} / \mathrm{cm}^{3}$.

\section{Acknowledgments}

The research was supported by the Russian Science Foundation (grant No. 19-19-00192) as well as by the Governmental program "Science", research project No. 11.3683.2017/4.6.

\section{References}

[1] Abraham T 2004 Powder Market Update: Nanoceramic Applications Emerge Am. Cer. Soc. Bull. 83(8) p 23

[2] Schmidt M, Spieth H, Haubach C et al 2019100 Pioneers in Efficient Resource Management (Springer Spektrum: Berlin, Heidelberg)

[3] Takiguchi T 2019 Appl. Sci. 9(5)

[4] Canumalla S, Gordon G A and Pangborn R N 1992 J. Eng. Mater. Technol. 119(2) 143-7

[5] Windsheimer H, Travitzky N, Hofenauer A and Greil P 2007 Laminated Objects Manufactoring of Preceramic Paper-Derived Si-SiC Composites Adv. Mater. 19 4515-9

[6] Travitzky N, Windsheimer H, Fey T and Greil P 2008 Preceramic Paper-Derived Ceramics $J$. Am. Ceram. Soc. 91 chapter $113477-92$

[7] Yurovskikh A S, Demakov S L, Kolosova E V 2013 Special features of the structure and phase composition of $\mathrm{A} \mathrm{Ti}-23 \mathrm{Al}-26 \mathrm{Nb} / \mathrm{Al}$ layered material obtainedby plasma-spark sintering 2013 Material Science and Heat Treatment 54 466-71

[8] Räthel J, Herrmann M and Beckert W 2009 Temperature distribution for electrically conductive and non-conductive materialsduring field assisted sintering (FAST) J. Europ. Ceram. Soc. 29(8) p 1419

[9] Holmquist T J, Rajendran A M, and Templeton D W 1999 A Ceramic Armor Material Database (U. S. Army Tank Automotive Research, Development and Engineering Center, Warren, Michigan) 